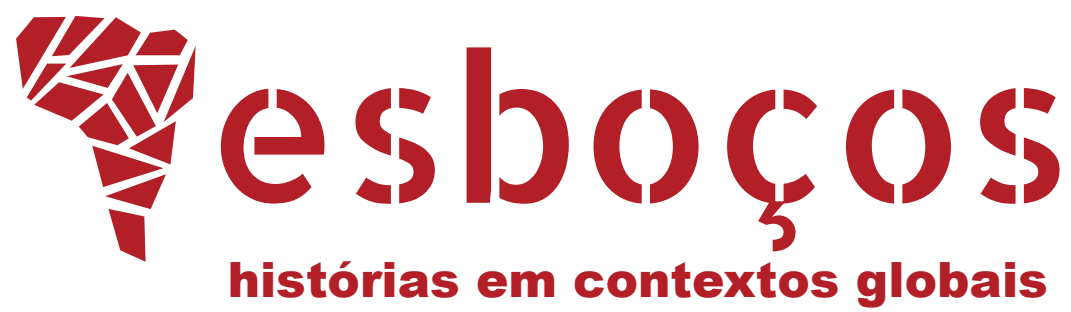

\title{
OUTRA HISTÓRIA GLOBAL É POSSÍVEL? DESOCIDENTALIZANDO A HISTÓRIA DA HISTORIOGRAFIA E A HISTÓRIA ANTIGA
}

Another Global History? De-Westernizing the History of Historiography and Ancient History

Uiran Gebara da Silva ${ }^{a}$ 


\title{
RESUMO
}

Este artigo traz, em sua primeira parte, uma reflexão sobre a problematização da história global como uma novidade historiográfica feita por Jurandir Malerba ao analisar seu impacto na área da história da historiografia. Ainda nessa parte, o artigo busca ressaltar a centralidade da crítica ao eurocentrismo e do impulso de desocidentalização na história global recente. Na segunda parte, com base numa comparação com os impactos da história global na História Antiga, reflito sobre os quatro pontos críticos apresentados por Malerba em suas considerações finais: o fato de objetos históricos poderem se beneficiar de uma abordagem global; a coerência narrativa e argumentativa possível aos tais objetos; os limites da expertise acadêmica para uma história global; a obsolescência prematura da história global. Na conclusão, afirma-se a singularidade da crítica desocidentalizadora na nova história global e a necessidade de os intelectuais do Sul global articularem suas histórias globais alternativas às dos intelectuais do Norte global.

\section{PALAVRAS-CHAVE}

História Global. História Antiga. Desocidentalização.

\begin{abstract}
This article brings, firstly, a reflection on the problematization of Global History as a historiographical novelty posed by Jurandir Malerba in his analysis of its impact in the field of History of Historiography. Also on this subject, the article underlines the importance of the critique to eurocentrism and the impulse towards the de-Westernization of recent Global History. The second part of this article is based on a comparison of the impact of Global History on Ancient History, where I address the four critical points presented by Malerba in his final remarks: the advantages of performing a global analysis in historical objects; the narrative and argumentative coherence possible for such objects; the limits of academic expertise in respect to Global History and the premature obsolescence of Global History. The conclusion states the particularities of the de-westernizing critique in the new Global History and the need for Global south historians to articulate their global histories as an alternative to the ones created by global north scholars.
\end{abstract}

\section{KEYWORDS}

Global History, Ancient History. De-Westernization. 
m seu artigo "História da historiografia e perspectiva global: um diálogo possível?", Jurandir Malerba (2019) propõe abordar a consolidação da história global como uma modalidade historiográfica. O objeto imediato do artigo é o que poderíamos chamar de uma "história global da história da historiografia", um objeto problematizado por meio da reflexão sobre dificuldades, desafios e potencialidades que seriam resultado da aplicação da história global à história da historiografia. Minha intenção neste artigo é dialogar com a reflexão feita por Malerba sobre a escrita de uma história global da história da historiografia e, segundo os impactos da nova história global no campo da História Antiga, pensar os limites e as potencialidades dessa abordagem.

$\mathrm{Na}$ primeira parte, partindo da leitura do texto de Malerba, reflito sobre a classificação da história global como uma novidade historiográfica e busco enfatizar que o que há de novo é a centralidade da crítica ao eurocentrismo e do impulso de desocidentalização na história global recente. Na segunda parte, baseando-me nos quatro pontos críticos apresentados por Jurandir Malerba em suas considerações finais, analiso os impactos da história global na História Antiga e como isso se relaciona com o processo de provincialização da história europeia.

O ponto de partida do texto de Malerba é a problematização da abordagem chamada história global. O caminho escolhido, porém, gera algumas "ratoeiras argumentativas" para o próprio autor. O texto se inicia com riscos de não levar a sério o próprio objeto, ao delinear o desenvolvimento dessa perspectiva, entre o fim da década de 1990 e o início do século XXI, dentro de uma armação narrativa que a enquadra numa sequência de "modas historiográficas".

Aqui é forçoso reconhecer que essa abordagem dentro da história talvez seja uma das poucas "modas" que de fato merecesse o adjetivo "nova". Essa "nova história global" é nova porque sempre houve histórias globais (mundiais ou universais). Mesmo sob o regime de uma historicidade moderna que fragmenta a narrativa e o enfoque com o enquadramento sob as histórias nacionais, algum tipo de história mundial, eurocêntrica e ocidentalizante esteve sempre pressuposta (CROSSLEY, 2008; FILLAFER, 2017).

Ao longo dos séculos XIX e XX, muitas histórias do mundo generalizantes e eurocêntricas, ao serem escritas, transformaram esse pressuposto em algo explícito (JONES, 1981; MCNEILL, 1963; SPENGLER, 1964; TOYNBEE, 1986; WELLS, 1939). É bastante importante reconhecer que, apesar de recorrer no início ao lugar-comum das "modas historiográficas", logo Malerba oferece ao leitor uma descrição dessa abordagem que faz jus ao olhar não eurocêntrico e desocidentalizante que a atual história global tem como ponto de partida.

Como sua estratégia de reflexão e lógica de argumentação visam abordar a consolidação da história global não em termos genéricos, mas partindo dos impactos dessa abordagem sobre um campo bem específico, é com base nos efeitos sobre o campo da história da historiografia que ele constrói a análise. Essa opção de delimitação do problema a ser analisado num terreno conhecido é de fato bem-vinda. Continuando com metáforas militares, a melhor forma de lidar com uma nova modalidade historiográfica em momento de expansão, conquista e consolidação de territórios no campo historiográfico é fazendo uma reflexão sobre seus potenciais e limites dentro de uma área específica em tal campo em processo de conquista.

Ao refletir acerca do impacto inicial da nova história global sobre a história da historiografia, é muito significativo que Malerba revele que aquele olhar não eurocêntrico 
só aparece no fim do século XX, uma vez que, durante muito tempo, foram justamente as obras canônicas da historiografia do XIX e do XX e, paralelamente, a história da historiografia produzida então que desenvolveram e elaboraram justificativas ideológicas para o eurocentrismo e o nacionalismo que ainda se associa à história como disciplina. ${ }^{1}$

Como o autor nos mostra, se é internamente ao campo da história da historiografia que a desconstrução dessas justificativas se inicia, com um movimento na direção do comparativismo transcultural, essa caminhada em direção a uma perspectiva global ganha impulso com o ingresso de autores não ocidentais que começaram a integrar o campo.

Outro elemento importante para essa reflexão diz respeito ao método da história global. Global não designa apenas o olhar abrangente, mas a percepção de articulações que transcendem recortes espaciais locais, nacionais e regionais. Ou seja, a história global não é só a escrita de uma narrativa global sobre tudo no globo desde o começo dos tempos, e sim o estudo daquelas articulações em nível inter-regional, macrorregional ou global, que devem ser pertinentes para o estudo de um fenômeno histórico específico. Como observa Malerba (2019, p. 462):

\begin{abstract}
A história global, em suas formulações mais sofisticadas, não significa contar a história de tudo no mundo todo. Podemos partir do entendimento de que "global" não é o objeto de estudo, qualquer que seja, mas uma ênfase nas conexões, na escala e, acima de tudo, na integração. Não é difícil imaginar uma história de mercados mundiais ou bolsas de valores numa economia global; uma história de disseminação de tecnologias como o telégrafo, o cabo marítimo ou a internet, conectando diferentes regiões do mundo; uma história de migrações e diásporas de populações sobre o globo; uma história dos hábitos alimentares ou da propagação de doenças mundo afora; uma história da guerra, com batalhas sucedendo simultaneamente em diferentes continentes.
\end{abstract}

Assim, embora haja exceções que tendam a resgatar a velha história mundial, com frequência os objetivos dessa história global não são somente a escrita de uma história do mundo como totalidade, mas a aproximação gradual dessa totalidade por meio de narrativas-problema e da observação de fenômenos históricos globais, ou de fenômenos locais vistos sob uma perspectiva global. É por isso que a história global se desenvolveu junto com a exploração dentro da pesquisa histórica de um conjunto de conceitos e metodologias que dialogam com esse tipo de objeto: conectividade, integração, movimento entre fronteiras, contatos, redes, comparativismo etc. (CONRAD, 2016).

A segunda parte do texto de Malerba, que enfoca a análise nos sucessos e nos insucessos de duas obras recentes, é bastante ilustrativa dos dilemas acima descritos. $\mathrm{Na}$ primeira obra, de Iggers, Wang e Mukherjee, a pluralidade de perspectivas e a preocupação em situar o pensamento historiográfico em culturas históricas e em processos sociais localizados no tempo e no espaço, vistos sob a óptica das

\footnotetext{
${ }^{1}$ Em particular na obra de Leopold von Ranke, cf. Chesneaux (1995) e Filafer (2017).
} 
noções associadas de globalização e modernização, resulta numa perspectiva que problematiza a normatividade dos modelos ocidentais para uma história global da história da istoriografia, ao mesmo tempo que propõe um modelo baseado na integração de tradições historiográficas.

Já a segunda obra analisada, de Woolf, apresentaria mais dificuldades e, portanto, mais pontos sobre os quais problematizar uma história global da história da historiografia. Aqui, a preocupação com o foco na escrita autoral e nas obras como contribuições autônomas resulta em contradições entre os pressupostos teóricos enunciados inicialmente, de provincianização da Europa, e os modelos de análise de fato empregados: um comparativista para as obras historiográficas anteriores ao século XIX - correspondendo à concepção de histórias paralelas das civilizações até o lluminismo - e um difusionista, que reproduz uma normatividade ocidentalista para as obras posteriores a esse recorte.

É significativo que nessa segunda obra e em sua conclusão, com a ideia de fragmentação das abordagens historiográficas alimentada por uma assim chamada "massificação", esteja a chave para a produção daquela sensação exasperante de "modas historiográficas" com a qual Malerba começa o artigo. Tal sensação é resultado do modo de produção historiográfica correspondente à cultura do capitalismo tardio (JAMESON, 1996), com o trabalho dos historiadores sendo determinado, por um lado, pela ultraespecialização e pela intensificação de um diálogo internacionalizado embora ainda tendo o Norte global como seu centro - e, por outro, pela fragmentação e pela conformação às correntes teóricas temporariamente vigentes.

Como historiador cuja especialidade não é história da historiografia, e sim História Antiga, posso dizer que a reflexão sobre limites e potencialidades da história da historiografia em perspectiva global apresentada por Malerba é também pertinente para minha própria área de especialização. Digo isso não só no que diz respeito às dificuldades que uma história global da história da historiografia enfrenta ao lidar com a historiografia da Antiguidade, que durante muito tempo foi tomada como origem mítica da "historiografia do Ocidente". Digo isso também no que concerne ao modo como seus questionamentos ressoam com os dilemas da aplicação dessa história global à investigação histórica propriamente dita sobre as sociedades da Antiguidade oriental e mediterrânica.

\section{DESOCIDENTALIZANDO A HISTÓRIA ANTIGA}

Gostaria agora, encaminhando-me para a segunda parte deste artigo, de traçar algumas considerações formuladas com base em meu próprio lugar disciplinar, tomando como eixo argumentativo os quatro elementos que Malerba elencou nas considerações finais de seu texto.

Os impactos da história global no campo de estudos da Antiguidade foram sentidos inicialmente de maneira indireta, mas depois se desdobraram em inúmeras direções. A História Antiga, até os anos 1980, podia ser seguramente considerada parte de uma história europeia, e o desenvolvimento de espaços de crítica possível a essa hermenêutica identitária sem mediações se dava apenas em áreas marginais do estudo da Antiguidade.

Tal é o caso de The World of Late Antiquity, de Peter Brown, que serve de marco inaugural para o desenvolvimento da área da Antiguidade tardia, obra que 
estabelece uma perspectiva de continuidade social e cultural não somente em termos temporais, entre os séculos III e VIII d.C., mas também em termos espaciais, com um mundo tardo-antigo que engloba da Irlanda às fronteiras da Pérsia com a Índia. Uma contribuição central da obra de Brown foi o enraizamento espacial da sua narrativa no corredor de sociedades formado pelo Mediterrâneo e pelo Planalto Iraniano (BROWN, 1971).

É difícil, dos anos 1970 até o início dos anos 2000, encontrar algo semelhante para os períodos considerados clássicos, a Grécia entre os séculos VI e IV a.C. ou o Império Romano - ele mesmo um mundo em si - em seu apogeu. Esse mundo greco-romano, como definido por Moses I. Finley $(1983,1999)$, se localizava no Mediterrâneo, mas era culturalmente definido com base num sistema de cidades-estados gregos e romanos considerados distintos dos vizinhos orientais e africanos - um sistema social excepcional cujos legados culturais, políticos e econômicos seriam herdados quase exclusivamente pela Europa.

O impacto gradual da crítica pós-colonial de fora, por meio das obras de Edward Said (2007) e Martin Bernal $(1987,2001)$, e de dentro, por meio dos trabalhos de David Mattingly, Susan Alcock (1997), C. R. Whittaker (1997), Jane Webster (2001), Partick Le Roux (2004), Richard Hingley (2010), Glen Bowersock (1994), entre outros, foi aos poucos desconstruindo aquela identificação primária com a narrativa do colonizador e habilitando investigações em escalas e recortes menores, nesse momento influenciadas pela história cultural dos anos 1980 e 1990.

Esse conjunto de trabalhos resulta no questionamento da identificação naturalizada dessa Antiguidade "greco-romana" com a Europa e o Ocidente. Faltava, então, apenas um movimento em direção à formulação de outros enquadramentos espaciais e temporais, que operassem tal distanciamento nas maneiras de organização e conformação dos recortes documentais e de unidades de análise. Isso se dá no princípio do século XXI, com o aparecimento de um conjunto de estudos que vai repensar o enquadramento espacial mediterrânico, assim como a duração e a temporalidade dessa Antiguidade (HARRIS, 2005; HORDEN; PURCELL, 2000; VLASSOPOULOS, 2007; WICKHAM, 2005).

Começarei pelo primeiro ponto indicado por Malerba: a reflexão sobre quais objetos históricos podem se beneficiar de uma abordagem global. O autor questiona se é possível investigar objetos globais anteriores à globalização. Mas eu me pergunto: qual globalização? Em paralelo ao desenvolvimento dessa história global, em diferentes recortes historiográficos surgiram tentativas de demonstrar a possível existência de outras globalizações, anteriores, alternativas, e a área da História Antiga não ficou imune a tais indagações.

Em verdade, já há uma razoável quantidade de estudos que exploram a possibilidade de pensar o Mediterrâneo antigo como uma das primeiras experiências de globalização (BROODBANK, 2013, 2014; GUARINELLO, 2013; HORDEN; KINOSHITA, 2014; PITTS; VERSLUYS, 2015; VLASSOPOULOS, 2013). Dentro desse contexto, podem-se pensar experimentos com objetos discretos de análise que permitam uma análise global, como é o caso do incenso ou da seda, ou verdadeiras reflexões sobre micro ou miniglobalizações na Antiguidade.

No primeiro caso, deve-se querer saber se existe um tipo de investigação historiográfica global que permite que o trabalho do historiador não seja só a compilação do trabalho de outros, e sim investigações diretas da documentação em perspectiva global. Já o segundo caso, mais generalizante e dificilmente realizável sem o apoio de 
literatura de segunda mão, é o que permite problematizar o esquema linear das eras da história universal eurocêntrica e propor novas temporalidades e espacialidades, ao buscar novos enquadramentos narrativos e descritivos, propondo unidades de análise alternativas baseadas em amplos sistemas de conexões e interações afroeurasianas. ${ }^{2}$

Especificamente na área da Antiguidade tardia, há uma importante exceção no que diz respeito ao estudo direto das fontes. O magnum opus de Chris Wickham, Framing the Early Middle Ages, consegue se apoiar no estudo direto da documentação escrita e arqueológica e, ao mesmo tempo, na leitura de (quase) toda a literatura crítica disponível. Aqui é exatamente a impossibilidade linguística de lidar diretamente com material persa que impôs a Wickham o limite do seu recorte a "apenas" a Europa, o norte da África e o Oriente Próximo (2005).

De todo modo, o que Malerba aponta é uma não coincidência entre objetos globais no passado e histórias globais. Nem toda investigação em história global lida com totalidades sociais globais ou globalizantes; algumas delas lidam com fenômenos históricos específicos com potencial de "mundialização" - mesmo que esse mundo seja um diminuto orbis terrarum romano integrado ao eransahr persa (HUMPFRIES, 2017).

Outras investigações são de fato experimentos de enquadramento temporal e espacial com unidades sociais globalizantes e que têm ajudado a desconstruir, no contexto da História Antiga, as forminhas epocais recebidas da tradição de historiografia europeia oitocentista (GUARINELLO 2003; 2013).

Isso se conecta com o segundo elemento crítico apontado por Malerba: o problema da coerência narrativa e argumentativa possível para objetos globais. Um argumento puramente descritivo e analítico, contudo, é mais fácil de alcançar nesses casos. Todavia, uma argumentação que lide com os processos e as transformações, que se entrelace com a narrativa global, não muito. Tanto no primeiro caso, o de objetos discretos globais, quanto no segundo, o de visões históricas globalizantes, o historiador global lida de fato com objetos amplamente complexos, mas o desafio aqui é como articular narrativa, temporalidades e espacialidades coerentes e que ao mesmo tempo se libertem do núcleo narrativo baseado na ideia de uma Europa fagocitária, na temporalidade linear e evolucionista, e na espacialidade imperialista.

O problema não é o tamanho dos objetos, mas nossos hábitos mentais ainda acostumados (ou acorrentados) a pensar a narrativa histórica unificada nos termos postos por Leopold von Ranke no início do século XIX e ainda reproduzidos por Finley nos anos 1970. Um exemplo de experimento narrativo e argumentativo no campo da Antiguidade que considero bem-sucedido é o estudo de Nicholas Purcell, que, partindo de um objeto de análise global, o incenso, joga com mudanças de escalas e integra procedimentos tanto da história global quanto da micro-história, de forma a apresentar conexões, integrações e crises em torno do fluxo comercial e cultural associado a esse objeto, articulando variações no recorte espacial e na temporalidade

\footnotetext{
2 Genaro Ascione (2016) desenvolve muito bem as razões de ter em conta a centralidade e a urgência de associar o debate sobre os recortes espaciais e temporais da história global com uma reflexão sobre as unidades de análise, especificamente no sentido de impedir que o eurocentrismo se reinstale. $O$ artigo de Ascione pode muito bem ser articulado às sugestões, um tanto heterogêneas, que aparecem na importante reflexão sobre a espacialização da investigação histórica (e sua interação com múltiplas escalas) e seu impacto sobre unidades de análise propostas por Belich, Darwin, Frenz e Wickham (2016).
} 
da circulação da Antiguidade à Idade Média, sem nunca perder de vista a dimensão narrativa desses processos (PURCELL, 2016).

O terceiro ponto, a escrita de uma obra de história global feita por um único autor e os limites da expertise acadêmica, apresenta de fato um grande desafio. Aqui, acredito que haja uma importante diferença entre estudos de objetos globais e prospecções globalizantes. Nos primeiros, há casos efetivamente existentes de trabalhos de pesquisa baseados em arquivos e documentação de diversas partes do globo, mas ainda assim autorais (SUBRAHMANYAM, 1997). Para as prospecções globalizantes, as dificuldades apontadas por Malerba são precisas. Nem tanto porque ninguém pode ser especialista de tudo, e sim, novamente, porque os velhos hábitos demoram a morrer.

A especialização é uma condição fundamental da maneira como se pratica a ciência no mundo moderno, porém não é exatamente essa a adversidade. O problema está na nossa enorme dificuldade em pensar o trabalho de investigação histórica em termos intra e interdisciplinares. Uma construção desse porte deve necessariamente ser coletiva, mesmo que realizada em termos autorais e reconhecendo a corveia não tão anônima dos contemporâneos de tal autor.

Levando em consideração o segundo e o terceiro elementos críticos apontados por Malerba, o melhor exemplo das potencialidades desse tipo de empreendimento historiográfico no campo da história antiga, mesmo quando autoral, é exatamente a obra responsável pelo impulso a uma história global da Antiguidade: The Corrupting Sea, de Peregine Horden e Nicholas Purcell (HORDEN; PURCELL, 2000). Ao levar a sério a produção de uma história ecológica e social do Mar Mediterrâneo, e tomando como ponto de partida a realização de uma série de seminários interdisciplinares com inúmeros colegas, os autores problematizaram a naturalização historiográfica da Antiguidade e da Idade Média como "origens da Europa ou do Ocidente", oferecendo, assim, a primeira organização narrativa da história das sociedades naquela região em termos de seus processos cíclicos de conexão e integração, fragmentação e crises. É ao mesmo tempo uma visão autoral e inter e intradisciplinar.

O quarto elemento crítico, habilitado pela leitura do artigo de Jeremy Adelman na Aeon (2017), trata especificamente dos limites da moda da história global. Aliás, para nós, historiadores brasileiros na segunda década do século XXI, é perturbador ler um texto como o de Adelman pregando o desaparecimento de uma "moda" que acabou de começar a influenciar os trabalhos por aqui. ${ }^{3}$ De toda forma, os problemas apontados por Adelman são reais e pertinentes. Peço licença aqui para me apropriar de ideias de Gayatri Spivak (2010, p. 47-76), pois o problema da língua inglesa como globalês é também consequência da permanência de formas colonialistas de produção historiográfica, de uma violência epistemológica geopolítica, em que a língua inglesa é o sujeito oculto.

Dentro dessa geopolítica intelectual, na qual o Norte global serve de campo seguro para a reflexão, a produção intelectual realizada no escopo da história global

\footnotetext{
${ }^{3}$ Aqui cabe uma consideração importante sobre a recepção brasileira da história global. A despeito do que afirmam Marquese e Pimenta (2015), penso que a maioria das tradições historiográficas latino-americanas das quais eles tratam, por mais emancipatórias que sejam as perspectivas por elas desenvolvidas, funciona num registro eurocêntrico e, portanto, tem diferenças importantes em relação à atual modalidade de história global.
} 
tendeu a favorecer os processos de conexão, contato e integração; a focalizar a criação de redes e de espaços cosmopolitas de trocas e inclusões culturais, sob a égide daquele sujeito oculto; a subvalorizar as formações de fronteiras, de interrupções de contato e desarticulações de redes; e a ignorar crises e processos de desintegração social.

No que diz respeito ao quarto elemento crítico, The Corrupting Sea, é bastante criticável, enquanto Framing the Early Middle Ages consegue incluir essa dimensão de maneira muito coerente. O primeiro, ao colocar como pressuposto social e natural da sua análise a fragmentação geográfica, ecológica e social do Mediterrâneo enfatizando a indistinção na longa duração entre campo e cidade o descentramento das relações de poder e a efemeridade das instituições, construindo uma narrativa baseada em fluxos e conexões transitórias, com intensificações e decréscimos de exploração do trabalho e riquezas -, apresenta uma narrativa na qual a organização política e a intencionalidade dos sujeitos históricos desaparece sob essas estruturas fragmentadas e voláteis. Com base nesse olhar, a agência humana desaparece, e o sofrimento e a opressão dos processos de integração e drama social das desintegrações ficam difíceis de ser compreendidos.

O segundo, ao buscar delinear as estruturas de poder político - os padrões de concentração urbana e dispersão rural, as formações de classe e diferenciação social, assim como as formas de produção e reprodução social, circulação e conflitos dali resultantes, sem nunca perder de vista a transitoriedade e a fluidez desses processos -, enfatiza a necessidade de observar todos esses níveis com o entrecruzamento e o desenlace de múltiplas histórias e linhas de desenvolvimento. O Império Romano é pensado como uma experiência de integração suprarregional, e a história subsequente do Mediterrâneo, como a narrativa de regionalizações da economia, da política e da cultura. Se o Império Romano articula politicamente múltiplas histórias provincianas, - Mediterrâneo pós-romano é o desenlace e o reencontro dessas várias histórias regionais e locais em outros quadros de poder, de cultura e de organização econômica, assim como de agência das classes subalternas.

\section{CONSIDERAÇÕES FINAIS}

É necessário concordar com Malerba quando afirma que "não é difícil argumentar que a história global é mais uma invenção eurocêntrica para integrar o 'outro' numa narrativa cosmopolita em nossos próprios termos". Eu só alteraria esse "nossos" por um "seus", pois acho que a historiografia brasileira não é uma parte imediata desse sujeito eurocêntrico, mas no máximo uma historiografia agregada, secundária, desse sujeito historiográfico eurocêntrico, só verdadeiramente respeitada quando trata da história do seu enquadramento nacional-provinciano. Da mesma forma, em certos momentos, a história global realmente "soa como a oficial do mundo de mercado globalizado, que enfatiza a narração de histórias sem fronteiras sobre a de uma suposta "aldeia global", de modo a dar à globalização uma face mais humanizada" (MALERBA, 2019, p. 468).

Ainda assim, nada disso é novidade para quem acompanha o debate conceitual sobre a globalização desde os anos 1990. Os dilemas da história global são os próprios dilemas da globalização do fim do século XX. Os possíveis problemas de uma história global eufórica são os mesmos da globalização eufórica (CHESNAIS, 1996; IANNI, 2007). As duas soluções sugeridas ao fim do artigo são imprescindíveis. 
É preciso que se busquem, em primeiro lugar, um verdadeiro cosmopolitismo historiográfico e uma abertura cultural que abranja mais línguas e linguagens, bem como mais formas narrativas. Em segundo lugar, também é necessário que se inclua na problemática, na observação empírica, na argumentação e, por fim, na narrativa dessas histórias globais o que Malerba chama de lado negro da força: "a desintegração, a opressão, a exploração e a resistência" (2019, p. 469). Consequentemente, é importante que essa história global seja interdisciplinar e que sua produção e elaboração busquem quebrar a divisão internacional do trabalho historiográfico. Mas o primeiro passo nessa direção, um passo no nível dos pressupostos teóricos, está dado: ao manter o foco na desconstrução do eurocentrismo e do ocidentalismo, essa história global, mesmo com seus passos para o lado e recuos, opera um importante trabalho de emancipação da narrativa histórica.

Trata-se de entender como as narrativas eurocêntricas sobre o aparecimento do capitalismo, da modernidade e da globalização recente suprimiram e reinventaram à sua imagem as histórias do resto do mundo (CHAKRABARTY, 2000). Trata-se também, a partir de agora, de caminhar na direção de repensar a história do mundo nos termos da sua pluralidade de histórias, incorporando experiências com a temporalidade e a espacialidade. Ou, parafraseando um importante mote crítico da globalização, tornado célebre ao longo do início do século XXI: outra história global é possível.

\section{REFERÊNCIAS}

ADELMAN, J. Is global history still possible, or has it had its moment? Aeon, 02 March, 2017. Disponível em: https://aeon.co/essays/is-global-history-still-possible-orhas-it-had-its-moment. Acesso em: 25 abr. 2019.

ASCIONE, G. Decolonizing the 'Global': The Coloniality of Method and the Problem of the Unit of Analysis. Cultural Sociology, Durham, v. 10, n. 3, p. 1-18, 2016.

BELICH, J. et al. Introduction: The Prospect of Global History. In: BELICH, J. et al. The Prospect of Global History. Oxford: Oxford University Press, 2016. p. 3-22.

BERNAL, M. Black Athena: The Afroasiatic Roots of Classical Civilization. New Brunswick: Rutgers, 1987.

BERNAL, M. Black Athena Writes Back: Martin Bernal Responds to His Critics. Urham \& London: Duke University Press, 2001.

BOWERSOCK, G. W. Roman Arabia. Cambridge: Harvard University Press, 1994.

BROODBANK, C. The Making of the Middle Sea: A History of the Mediterranean from the Beginning to the Emergence of the Classical World. London: Thames \& Hudson, 2013.

BROODBANK, C. Mediterranean "Prehistory". In: HORDEN, P.; KINOSHITA, S. (ed.). A Companion to Mediterranean History. Oxford: John Wiley \& Sons, 2014. p. 43-58. 
BROWN, PETER. The World of Late Antiquity. London: Routledge, 1971.

CHAKRABARTY, D. Provincializing Europe: Postcolonial Thought and Historical Difference. Princeton: Princeton University Press, 2000.

CHESNEAUX, JEAN. Devemos fazer tábula rasa do passado? Sobre história e historiadores. São Paulo: Ática, 1995.

CHESNAIS, F. A mundialização do capital. São Paulo: Xama, 1996.

CONRAD, S. What Is Global History? Princeton: Princeton University Press, 2016.

CROSSLEY, P. K. What is Global History? Cambridge: Polity, 2008.

FILLAFER, F. L. A World Connecting? From the Unity of History to Global History. History and Theory, Middletown, v. 56, n. 1, p. 3-37, 2017.

FINLEY, M. I. Politics in the Ancient World. Cambridge: Cambridge University Press, 1983.

FINLEY, M. I. Ancient Economy. Berkeley: University of California, 1999.

GUARINELLO, N. L. Uma morfologia da história: as formas da História Antiga. Politéia-História e Sociedade, Vitoria da Conquista, v. 3, p. 41-62, 2003.

GUARINELLO, N. L. História Antiga. São Paulo: Contexto, 2013.

HARRIS, W. V. (ed.). Rethinking the Mediterranean. Oxford: Oxford University Press, 2005.

HINGLEY, R. O Imperialismo romano: novas perspectivas a partir da Bretanha. São Paulo: Annablume, 2010.

HORDEN, P.; PURCELL, NICHOLAS. The Corrupting Sea: A study of Mediterranean History. Oxford: Blackwell, 2000.

HORDEN, P.; KINOSHITA, S. (ed.). A companion to Mediterranean history. Chichester, West Sussex: Wiley Blackwell, 2014.

HUMPFRIES, M. Late Antiquity and World History. Challenging Conventional Narratives and Analyses. Studies in Late Antiquity, Baltimore, v. 1, n. 1, p. 9-37, 2017.

IANNI, O. Teorias da globalização. Rio de Janeiro: Editora Record, 2007.

JAMESON, F. Pós-modernismo: a lógica cultural do capitalismo tardio. São Paulo: Ática, 1996. 
JONES, E. The European Miracle: Environments, Economies and Geopolitics in the History of Europe and Asia. Cambridge: Cambridge University Press, 1981.

LE ROUX, P. La romanisation en question. Annales HSS, Paris, v. 59, n. 2, p. 287311, 2004.

MALERBA, Jurandir. História da historiografia e perspectiva global: um diálogo possível? Esboços, Florianópolis, v. 26, n. 43, p. 457-472, set./dez. 2019.

MARQUESE, R. D. B.; PIMENTA, J. P. Tradições de história global na América Latina e no Caribe. História da Historiografia, Ouro Preto, n. 17, abr. 2015.

MATTINGLY, D. J.; ALCOCK, S. E. (ed.). Dialogues in Roman Imperialism: Power, Discourse, and Discrepant Experience in the Roman Empire. Portsmouth: JRA, 1997.

MCNEILL, W. H. The Rise of the West: A History of the Human Community. Chicago: University of Chicago Press, 1963.

PITTS, M.; VERSLUYS, M. J. Globalisation and the Roman World: Archaeological and Theoretical Perspectives. Cambridge: Cambridge University Press, 2015.

PURCELL, Nicholas. Unnecessary Dependences: Illustrating Circulation in Premodern Large-scale History. In: BELICH, J. et al. (ed.). The Prospect of Global History. Oxford: Oxford University Press, 2016. p. 65-79

SAID, E. Orientalismo. São Paulo: Companhia das Letras, 2007.

SPENGLER, O. A decadência do ocidente: esboço de uma morfologia da história universal. Rio de Janeiro: Zahar, 1964.

SPIVAK, G. C. Pode o subalterno falar? Belo Horizonte: UFMG, 2010.

SUBRAHMANYAM, S. Connected Histories: Notes towards a Reconfiguration of Early Modern Eurasia. Modern Asian Studies, Cambridge, v. 31, n. 3, p. 735-762, 1997.

TOYNBEE, A. Um estudo da história. Brasília/São Paulo: UNB/Martins Fontes, 1986.

VLASSOPOULOS, K. Unthinking the Greek Polis: Ancient Greek History beyond Eurocentrism. Cambridge: Cambridge University Press, 2007.

VLASSOPOULOS, K. Greeks and Barbarians. Cambridge: Cambridge University Press, 2013.

WEBSTER, J. Creolizing the Roman Provinces. American Journal of Archaeology, Boston, v. 105, n. 2, p. 209-225, 2001. 
WELLS, H. G. História universal. Rio de Janeiro: Companhia Editora Nacional, 1939.

WHITTAKER, C. R. Frontiers of the Roman Empire: a Social and Economic Study. Baltimore: Johns Hopkins University Press, 1997.

WICKHAM, C. Framing the Early Middle Ages: Europe and the Mediterranean 400800. Oxford: Oxford University, 2005.

\section{NOTAS}

\section{AUTORIA}

Uiran Gebara da Silva: Doutor. Professor adjunto, Universidade Federal Rural de Pernambuco, Departamento de História, Recife, PE, Brasil.

\section{ENDEREÇO PARA CORRESPONDÊNCIA}

Rua Manoel de Almeida, 117, ap 302, 52011-140, Graças, Recife, PE, Brasil.

\section{FINANCIAMENTO}

Não se aplica.

\section{APROVAÇÃO DE COMITÊ DE ÉTICA EM PESQUISA}

Não se aplica.

\section{CONFLITO DE INTERESSES}

Não houve conflitos de interesses.

\section{LICENÇA DE USO}

Este artigo está licenciado sob a Licença Creative Commons CC-BY. Com essa licença você pode compartilhar, adaptar, criar para qualquer fim, desde que atribua a autoria da obra.

\section{PUBLISHER}

Universidade Federal de Santa Catarina. Programa de Pós-Graduação em História. Portal de Periódicos UFSC. As ideias expressadas neste artigo são de responsabilidade de seus autores, não representando, necessariamente, a opinião dos editores ou da universidade.

\section{EDITORES}

Alex Degan

Beatriz Mamigonian

Fábio Augusto Morales

Flávia Florentino Varella (Editora-chefe)

Tiago Kramer de Oliveira

Waldomiro Lourenço da Silva Júnior

\section{HISTÓRICO}

Recebido em: 29 de maio de 2019

Aprovado em: 28 de agosto de 2019 